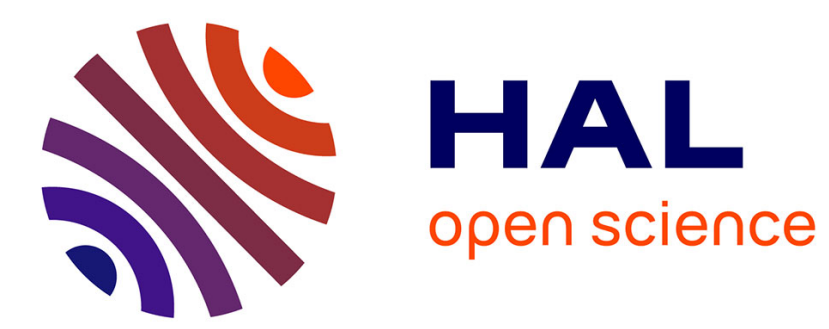

\title{
A Cognitive Analysis of the Perception of Shape and Motion Cooperation in Virtual Animations
}

Amel Achour Benallegue, Annie Luciani, Ali Allaoui, Saman Kalantari

\section{To cite this version:}

Amel Achour Benallegue, Annie Luciani, Ali Allaoui, Saman Kalantari. A Cognitive Analysis of the Perception of Shape and Motion Cooperation in Virtual Animations. SAP 2012 - ACM Symposium on Applied Perception, Aug 2012, Los Angeles, CA, United States. pp.x-x. hal-00827361

\section{HAL Id: hal-00827361 \\ https://hal.science/hal-00827361}

Submitted on 29 May 2013

HAL is a multi-disciplinary open access archive for the deposit and dissemination of scientific research documents, whether they are published or not. The documents may come from teaching and research institutions in France or abroad, or from public or private research centers.
L'archive ouverte pluridisciplinaire HAL, est destinée au dépôt et à la diffusion de documents scientifiques de niveau recherche, publiés ou non, émanant des établissements d'enseignement et de recherche français ou étrangers, des laboratoires publics ou privés. 


\title{
A Cognitive Analysis of the Perception of Shape and Motion Cooperation in Virtual Animations
}

\author{
Amel Achour Benallegue* \\ a.achour.benallegue@gmail.com \\ Annie Luciani*
Annie.Luciani@imag.fr \\ Ali Allaoui* ${ }^{+}$ \\ Saman Kalantari* \\ Ali.Allaoui@imag.fr Saman.Kalantari@imag.fr \\ *ICA Laboratory, Grenoble Institute of Technology, Grenoble, France \\ ${ }^{+}$Laboratoire XLIM, CNRS, Université de Poitiers, France
}

\begin{abstract}
In order to better understand perceptual and cognitive features of shapes and motions associations, we first create synthetic animation composed of realistic motions modeled by physical modeling mapped on abstract shapes. Second, we propose such paradoxical and surprising animations to subject's observations and we analyze them by qualitative analysis methods.
\end{abstract}

CR Categories: J.4 [Social and behavioral sciences]:

Psychology; H.5.1 [Information interfaces]: Animation; J.5

[Arts and humanities]: Arts, fine and performing.

Keywords: Computer animation, cognitive psychology.

\section{Overview of the method}

Animations are the perceptual material in the psycho-cognitive experiments. The building process of these animations consists in designing first a physical model for the motion by using the MIMESIS software [Evrard et al. 2006] and then by coating the motion by arbitrary abstract shapes, such as lines, surfaces, elementary volumes, or more complex quite realistic shapes such as representations of garments with tearing. Each motion is coated by three types of shapes, defined by differences in their topology, their geometry or their visual rendering. The mapping of a same motion on different coatings produces perception ambiguities. To determine the impact of these ambiguities on human perception and on the creativity sense, we developed a set of psychological and cognitive experiments. In the context of human studies, the appropriate domain for the work presented here is related to qualitative research methods, based on semistructured interviews and content analysis method [Flick 2002]. The experimental protocol is composed of 4 stages: 1) Presentation of built animations at each person. Figure 1 shows one of the five animations proposed, called "Blobby model". 2) Individuals watch three pairs of the designed videos, each pair containing the same motion. 3) Performing free interviews with individuals on their perception of animations. All the interviews are recorded on audiovisual support. 4) Focusing the discourses of the human subject onto a few major levels of the discourses: sensation, evocation, imagination and cognition.
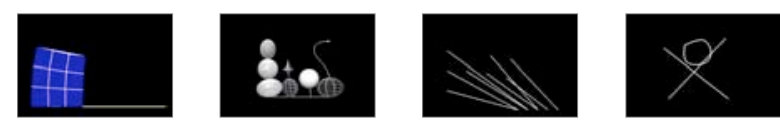

Figure 1: The "blobby model" and its abstract visual coatings

\section{Experimental results}

The experimentations analyses led us to two classes of observations: 1) those related to common subject's behaviors and 2) those related to the respective influences of both motions and shapes on the human perception.

The first main observation is that, despite our apprehension that participants would be annoyed when viewing these strange and often abstract videos, all participants were unanimously highly interested and stayed more than one hour in front of the videos for the experiment. The second main observation is that all participants considered animations as "intriguing". Participants set a hypothetic plausible scene and attempted to recognize it by several manners. This observation confirms results presented in [Luciani et al. 2007]. We can classify these interrogations into two main behaviors: (1) The reference to the real world by seeking real situations similar to the animation. (2) The exploration of pictures by abstract reasoning.

Behavior and reactions of subjects highlights two common stages of cognitive behavior: 1) the step of finding, where the subjects construct an idea of an inferred scene that possibly corresponds to the observed video. And 2) the step of comparison with cognitive schemas, where the person confronts the idea built during the stage of finding with personal knowledge schemas acquired in its past life. In the case of some compatibility, participants make assumptions and conclusions on the picture and its behavior. In the case of no compatibility, participants are faced to paradoxes and / or misunderstanding, that lead him/her to appreciate, to reject or question the seen scene, and to enter in what we called "an exploratory process", that confirms the theory of enaction [Stewart et al. 2010].

\section{Acknowledgements}

This work has been supported by the French Research National Agency within the research program "Contents and Interactions" - Project DYNAMé 09 CORD 007 01-02-03.

\section{References}

Evrard, M., Luciani, A., Castagné, N. 2006. MIMESIS: Interactive Interface for Mass-Interaction Modeling. CASA'06 proceedings, Computer Graphic Society, pp 177-186.

Flick, U. 2002. Qualitative research-state of the art. Social science information, pages 5-24.

Stewart, J., Gapenne, O., Di Paolo, E-A. 2010. «Enaction: Toward a new paradigm for cognitive science. MIT Press.

Luciani, A., O'Modhrain, S., Magnusson, C., Florens, J-L., Couroussé, D. 2007. "Perception of virtual multisensory mobile objects: wandering around the enactive assumption", Enactive / 07 enaction_in_arts Proceedings of the 4th International Conference on Enactive Interfaces 2007, ACROE, pp 153-156, 2007 